\title{
Cuba's Virtual Libraries: Knowledge Sharing for the Developing World
}

\author{
By Conner Gorry
}

The 10-90 gap, double burden of disease, lack of infrastructure, resource scarcity: developing countries face a series of circumstances and determinants which inhibit progress in population health. Add to this constellation of challenges another set related to knowledge sharing, including the "know-do" gap and the digital divide, and the barriers to health in the Global South loom larger still. Whereas there's no silver bullet for rebuilding crumbling health systems, information sharing holds possibilities for improving health care and services, especially in resource-scarce settings.

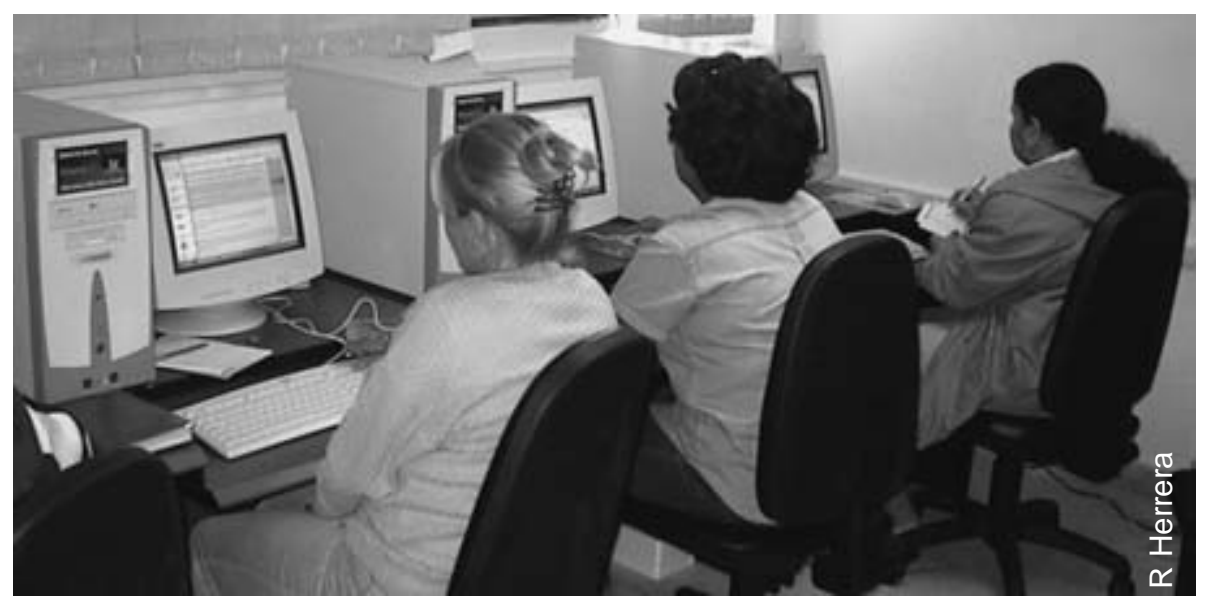

Students completing VHU course

Indeed, several studies have shown that more and better access to information by health professionals are among the most effective means to improve health outcomes in the developing world.[1,2] Despite the evidence however, international initiatives to help relevant, needs-driven information reach Global South health professionals have been slow to take hold. For instance, the International Network for the Availability of Scientific Publications (INASP) and 20 other international health organizations failed to secure funding for their Global Review on Access to Health Information in Developing Countries.[3] Implementing information and communication tools in developing countries is also hampered by connectivity problems: though it's called the World Wide Web, only $1 / 6$ of the world uses the Internet[4] and studies of institutional connection rates show African universities have, on average, a connection 500-600 times slower than US and European universities.[5] Cost can also serve as a barrier to access.

This paradigm is being challenged from some unlikely quarters - medical universities in post-war Bosnia Herzegovina and telehealth centers in rural Idaho for example - indicating that it's not only possible, but also practical to use information and communication technologies (ICTs) for knowledge sharing in the most resource-scarce and disadvantaged settings. Add to this list Cuba, where free and openly accessible virtual libraries form the backbone of scientific, medical, and health information sharing for health research, policy, and practice.

\section{The Virtual Health Library}

In 1998, Cuba was among the initial signatories to accords establishing the Virtual Health Library (VHL), a regional cooperation project between the Pan American Health Organization (PAHO) and member countries, coordinated by the Brazil-based Latin American and Caribbean Center on Health Sciences Information (BIREME). The stated purposes of the VHL are to:
1. Enable the widest access to information to improve population health through an integrated and cooperative regional strategy.

2. Create a tool for strengthening health systems and sustainable development of human resources for the region.[6]

Several guiding principles were laid out in the San Jose Declaration, the document calling for the founding of the $\mathrm{VHL}$, which specialists from Cuba's Health Care and Telecommunications Network and Portal (INFOMED), and the National Medical Sciences Information Center (CNICM, designated a WHO Collaborating Center for the VHL in 2005) helped shape. The guiding principles include:

- $\quad$ Promoting equitable access to relevant health information to improve outcomes regionally

- $\quad$ Fostering collaboration to maximize knowledge sharing

- Developing a decentralized system at every level of the library

- Developing a system that is reliable and relevant to local circumstances

- Applying integrated evaluation systems that emphasize best practices and quality control

These principles were further developed into a set of guidelines and methodology that must be followed by national VHLs in order to be incorporated into the regional network. The guidelines aim to ensure scientific quality of content, avoid duplication of efforts, and establish compatibility and interoperability between the separate libraries. Since the network is designed so that users are both consumers and producers of content, compatibility and interoperability issues are key to ensuring easy access to relevant content across national, cultural, and technological boundaries.

There are currently 25 countries with Virtual Health Libraries (see box), including two from the European Union, expanding 
the scope beyond PAHO members. Importantly, there are over 2,000 institutions actively creating, publishing, and accessing the knowledge within the VHLs.[6] In Cuba's case, the VHL and the INFOMED gateway itself, adhere to an open access policy in keeping with the government's commitment to developing a virtual information infrastructure on an open access platform (see Policy \& Practice: Cuba's National eHealth Strategy). This commitment has translated into a slow but steady connection of primary, secondary, and tertiary health care facilities to the national health portal, through which practitioners consult the VHL.

As of 2005 , the Virtual Health Library was accessible in all 444 community polyclinics throughout the country (with the addition of 1,700 new computers). Additionally, networks in all the country's Provincial Hygiene and Epidemiology Centers, HIVIAIDS treatment centers, Health Promotion Centers, and the National Medical Library were connected to the VHL, which was registering 4.2 million hits a month.[7] This traffic included visits from practitioners in Cuba's most remote rural municipalities and some of the 28,000 Cuban health professionals serving abroad. Rural connectivity was made possible through government funding, with additional support from the Global Fund to Fight AIDS, Tuberculosis and Malaria, and the Madrid Polytechnic University.

The Cuban VHL can be divided into three areas of knowledge available to users: information; medical education; and decision-making support. The first, information, is a collection of books, journals, databases (bibliographies, statistics, glossaries, medicines used in Cuba, etc.), and portals. Electronic publishing and the current health and epidemiological picture

\section{Scientific Publications \& Portals Available as Open Access in Cuba}

The following resources are provided free as part of a cluster of international and regional collaborations including the World Health Organization, Pan American Health Organization, and member countries to make scientific knowledge accessible to researchers and health practitioners in the Global South. Together these comprise Cuba's Virtual Health Library (www.bvscuba.sld.cu).

- BioMed Central

- MedLine

- DynaMed

- EBSCO Publications

- Health InterNetwork Access to Research Initiative (HINARI)

- $\quad$ Public Library of Science (PLoS)

- PubMed

- Literatura Latinomericana y del Caribe en Ciencias de la Salud (LILACS)

- $\quad$ Scientific Electronic Library Online (SciELO)

- Oxford Journals

- Cochrane Library

\section{Countries with Virtual Health Libraries}

Argentina
Barbados
Belize
Bolivia
Brazil
Chile
Colombia
Costa Rica
Cuba
Dominican Republic
Ecuador
El Salvador
Guatemala

Honduras
Jamaica
Mexico
Nicaragua
Panama
Paraguay
Peru
Portugal
Spain
Trinidad \& Tobago
Uruguay
Venezuela
Guatemala

both nationally and globally are areas of emphasis for information collection, with thousands of scientific journals available online (including over 30 Cuban scientific and medical journals available via SciELO), daily health news services, and weekly epidemiological bulletins.

With over 25,000 Cubans studying medicine and more than 71,000 already in practice,[8] the need for quality, continuing medical education is vast and ongoing. The medical education area of the Cuban VHL, with its ability to equitably and easily reach large numbers of students, is highly developed. Divided into the Virtual Classroom - part of Cuba's Virtual Health University, granting post-graduate degrees (See: The Virtual Health University: An eLearning Model within the Cuban National Health System) - and more specialized Supercourses, these are distance learning opportunities for large-scale education. Graduates from the Virtual Classroom include doctors, librarians, scientific editors, and provincial health directors, over 90 of whom have received diplomas in Health Information Management.

Decision-making applications and support are among the most direct mechanisms for improving basic and diagnostic health services. Whereas Cuba has a long history of store-and-forward clinical consultations both nationally and internationally (first via traditional mail and telephone and now using email), new ICTs are making synchronous collaboration possible between health professionals on the island and abroad. While still in its infancy due to technological and financial difficulties, the Virtual Clinic area of the Cuban VHL enables Cuban specialists to consult faster and more frequently with colleagues. The Virtual Clinic includes: clinical pathology consultations, diagnostic discussion forums, case study collaboration, image gallery, and "Ask an Expert."

The PAHO-BIREME network of virtual libraries also has sections dedicated to specific themes of particular importance to regional health practitioners, including bioethics, sustainable development and environmental health, and bird flu, among others. Cuba is an active participant in the thematic sections and is developing its own areas of specialist interest (see box). 


\section{Cuba's VHL: Thematic Areas in Development}

- $\quad$ Adolec-Cuba - Adolescent health

- Ambiente-Cuba - Environmental risk factors \& effects on population health

- APS - Primary health care

- $\quad$ CITESA - Science \& technology innovations for health

- Epidemiología-Cuba - Epidemiology \& health

- Infancia - Child health

- $\quad$ BVCIS - Information sciences for health professionals

- $\quad$ Salud y Desastres - Health and natural and manmade disasters

- Vigilancia - Health surveillance

\section{The Virtual Vaccine Library}

With the world's first internationally-marketed meningitis B vaccine, the first Haemophilus influenzae type b using a synthetic antigen, a recombinant hepatitis $B$ vaccine, and 100 registered patents with another 500 pending, (see MEDICC Review, Fall 2007, Vol 9, No 1), Cuba is uniquely positioned to share vaccinerelated knowledge with the region. The existence of a health portal (INFOMED) and experience with the VHL, combined with the $\mathrm{WHO}$ finding that "a number of websites providing unbalanced, misleading and alarming vaccine safety information...mak[e] it more difficult to identify and access reliable sources of information on the web,"[9] provided the impetus for the development of a specialized vaccine network. Furthermore, the WHO found only three websites providing accurate vaccine information on the web in Spanish - none from Latin America.[9]

Launched in 2006, the Virtual Vaccine Library (VVL, www.bvv. sld.cu) is part of a larger ongoing project called the Latin American Scientific \& Technical Vaccine Information Network (Vaccine Network for short).[10] The Vaccine Network incorporates the VVL, the Virtual Vaccine Classroom, and VacciMonitor, the peer-reviewed journal of Cuba's Finlay Institute, all three of which adhere to the same principles and mission as the VHL: to provide accurate, relevant, and accessible scientific information through regional cooperation and exchange. Methodology and guidelines for the Vaccine Network are modeled on those of the Virtual Health Library to ensure interoperability.

In order to create a fully integrated Latin American network of experts, specialized institutions from around the region were invited to collaborate in the Network's design and implementation from the project's inception. Institutions in Ecuador, El Salvador, and Colombia accepted the invitation as initiators, though the $\mathrm{Cu}$ ban contribution remains the most robust. Executive Committee member María Victoria Guzmán told MEDICC Review that quality and timely content generation by regional partners is the project's biggest challenge moving forward.

The Vaccine Network aims to expand and fortify the regional scholarly community of vaccine researchers and health practitioners administering those vaccines, plus offer reliable, up-to-date vaccine information to the general public. This is made possible through products and services grouped into the following categories:

- $\quad$ Reference - Includes original scientific articles and books by scientists in the region, vaccine-related news, epidemiological reports, etc.

- $\quad$ Regulations - Presents all national immunization plans for individual countries in the region, plus value-added information including FAQs, a manual for nurses, and each country's epidemiological profile.

- $\quad$ Market - Collects studies on the latest vaccines, their stages of development and clinical trials; details existing vaccines and parent company profiles and offers strategic analysis of the market.

- Industrial Property - Lists global vaccine patents and brand names, provides information on vaccine innovators, and has an interactive consultation section where specialists and health professionals can submit specific questions about $\mathrm{Cu}$ ban vaccines, their chemical components, immunogenicity, applicability, etc.

- $\quad$ Customer Service - A virtual center for commercial clients to submit technical questions about Cuban vaccine and biotechnology products (Cuban products are registered in over 55 countries, mostly in the Global South).

Between December 2006 and November 22, 2007, there were 74,427 visits to the VVL.[11] Users in countries accessing the Virtual Vaccine Library came from (in descending order): Cuba, Mexico, Peru, Argentina, Colombia, Spain, and Chile, among others.[12]

The Virtual Vaccine Classroom and VacciMonitor are both in different stages of integration into the Vaccine Network. The Virtual Vaccine Classroom is slated to officially launch in January 2008, with a course in Prevention \& Control of Meningococcal Disease.[13] This is following two pilot courses already completed in Biosecurity and Vaccine Pharmacovigilance. For it's part, VacciMonitor (founded in 1992), the official scientific publication of Havana's Finlay Institute, aims to broaden its editorial mission to include original peer-reviewed, vaccine-related research by scientists from other countries. In the near future, Vaccine Network architects will submit their platform for evaluation by the WHO's Global Advisory Committee on Vaccine Safety (GACVS) for inclusion on the organization's list of accredited vaccine sites.

\section{Conclusions}

Information and communication technologies present concrete opportunities for bridging the so-called know-do gap in scientific information sharing. What is known: when health professionals, especially in resource-scarce, underserved settings have free and open access to relevant and reliable information, outcomes improve. What to do: use information and communications technologies to bring that knowledge to people and places that need it. The Cuban experience shows that creativity, combined with a national strategy for developing virtual infrastructures, can lower barriers including limited bandwidth, lack of resources, and geopolitical isolation. Regional cooperation through virtual libraries and networks can strengthen, broaden, and extend that experience to the people who need it most. 


\section{Feature}

\section{References}

1. Pakenham-Walsh N, Priestly C, Smith R. Meeting the information needs of health workers in developing countries. BMJ 1997;314:90.

2. Godlee F, Pakenham-Walsh N, Ncayiyana D, Cohen B,. Packer A. Can we achieve health information for all by 2015 ? Lancet. 2004;364(9430):295-300.

3. The goal of the Global Review was to document the progress, experiences, lessons, and possible solutions regarding access to healthcare information between 1994 and 2004. The review was part of the project "Universal Access to Essential Health Information by 2015." See Pakenham-Walsh N, Bukachi F. INASP Newsletter. Nov 2004;27.

4. Global Internet use is projected to grow to $23.3 \%$ by 2010 . Qiang, C, ed. Information and Communications for Development 2006: Global Trends and Policies. Washington DC: The World Bank; 2006. Available from: www.worldbank.org/ic4d

5. Missen CC, Cook, TM. Appropriate information-communications technologies for developing countries. Bulletin World Health Organization. 2007;85(4):248.

6. Biblioteca Virtual de Salud de Cuba [homepage on the Internet]. Havana: INFOMED; c1999-2007 [updated 2007 Oct 15; cited 2007
Oct 15]. Acerca de la BVS Cuba; [about 6 screens]. (Translated by author). Available from: http://www.bvscuba.sld.cu/html/es/home.html

7. Biblioteca Virtual de Salud de Cuba; INFOMED. Informe del País, Septiembre de 2005. Havana; 2006.

8. Figures are provisional for 2006-2007. Dirección Nacional de Registros Médicos y Estadísiticas de Salud; Ministerio de Salud Pública. Anuario Estadístico de Salud, 2006. Havana: Ministerio de Salud Pública; 2007.

9. World Health Organization. Websites providing information on vaccine safety recognized for complying with good information practices. Geneva: World Health Organization. May 10, 2005.

10. The Latin American Vaccine Network grew out of Cuba's already existing Virtual Vaccine Network which facilitated exchange between scientists working in the country's biotechnology institutions known collectively as the Scientific Pole.

11. Biblioteca Virtual de Vacunas [homepage on the Internet]. Havana: INFOMED; c2006-2007 [updated 2007 Nov 22; cited 2007 Nov 22]. Estadísticas de Acceso www.bvv.sld.cu; [1 screen]. Available from: http://servicios.sld.cu/webalizer/www.bvv.sld.cu/

12. Red Latinoamericana de Información Científico-Técnica en Vacunas. FIINSA Conference Presentation. Havana: 2006.

13. Personal communication. María Victoria Guzmán. November 2, 2007. 